\title{
openheart Lorcaserin for the treatment of obesity? A closer look at its side effects
}

\author{
James J DiNicolantonio, ${ }^{1}$ Subhankar Chatterjee, ${ }^{2}$ James H O'Keefe, ${ }^{1}$ \\ Pascal Meier ${ }^{3,4}$
}

To cite: DiNicolantonio JJ, Chatterjee S, O'Keefe JH, et al. Lorcaserin for the treatment of obesity? A closer look at its side effects. Open Heart 2014;1:e000173. doi:10.1136/openhrt-2014000173

Accepted 1 October 2014

CrossMark

\begin{abstract}
${ }^{1}$ Mid America Heart Institute at Saint Luke's Hospital, Kansas City, Missouri, USA

${ }^{2}$ R.G. Kar Medical College \& Hospital, Kolkata,

West Bengal, India

${ }^{3}$ The Heart Hospital, University College London Hospitals, London, UK ${ }^{4}$ Yale Medical School, New Haven, Connecticut, USA
\end{abstract}

Correspondence to Dr James J DiNicolantonio; jjdinicol@gmail.com
Obesity is developing into a pandemic in countries like the USA, the UK and India. ${ }^{1-3}$ The WHO projects that by 2015 , about 700 million adults will be clinically obese. ${ }^{4}$ Obesity is a major public health problem, beyond the disability directly related to excessive adiposity, and it also increases the risk of several chronic diseases such as hypertension, sleep apnoea, diabetes, coronary artery disease and cancer. Clearly, obesity is a serious threat, imposing a vast economic burden on the healthcare system. ${ }^{5}$

Obesity is the second most common preventable cause of death, second only to tobacco use. ${ }^{6}$ Evidence suggests that weight reduction substantially lowers the risk of related comorbidities and fosters their therapeutic management. ${ }^{7} 8$ Although bariatric surgery has emerged as the most clinically effective strategy for decreasing body weight for people with morbid obesity (body mass index (BMI) $\geq 40$ ) or for those who cannot be managed otherwise, ${ }^{9}$ it is a very invasive procedure with significant risks. ${ }^{10}{ }^{11}$ At this juncture, behavioural therapy, lifestyle modification and pharmacotherapy remain the mainstays of treatment. The most appealing solution for the public in general would be a 'weight loss pill'. Several drugs have been tested since the 1960s, such as thyroid hormone, dinitrophenol, various forms of amphetamines, aminorex, fenfluramine, phenylpropanolamine, rimonabant, orlistat and sibutramine. All but phentermine, phendimetrazine and orlistat have been banned because of serious side effects. Aminorex was introduced in 1965 in Switzerland and was found to cause pulmonary hypertension. Lorcaserin (ADP356; Trade name: Belviq marketed by Arena Pharmaceuticals) and topiramate/phentermine (Qsymia) are the most recent additions to the armamentarium of antiobesity medications. ${ }^{12}$

Lorcaserin is a novel drug acting selectively as a $5-\mathrm{HT}_{2 \mathrm{C}}$ receptor agonist in the hypothalamus with a functional selectivity of 15 times higher affinity for $5-\mathrm{HT}_{2 \mathrm{C}}$ than for $5-\mathrm{HT}_{2 \mathrm{~A}}$ receptors and 100 times higher selectivity for $5-\mathrm{HT}_{2 \mathrm{C}}$ than for the $5-\mathrm{HT}_{2 \mathrm{~B}}$ receptors. ${ }^{13-15}$ It has achieved a clinically meaningful weight loss as per Food and Drug Administration's (FDA's) guidance criteria (2007), that is, a mean efficacy criterion (a medicationassociated (ie, greater than placebo) weight reduction of 5\%) and a categorical efficacy criterion (a significantly greater proportion (at least $35 \%$ ) of those individuals receiving the medication compared with placebo controls maintaining a $5 \%$ weight loss from their initial weight) ${ }^{16}$ Lorcaserin is indicated as an adjunct to a reduced-calorie diet and increased physical activity for the chronic weight management in adults with an initial BMI of $30 \mathrm{~kg} / \mathrm{m}^{2}$ or greater (obese) or $27 \mathrm{~kg} / \mathrm{m}^{2}$ or greater (overweight) in the presence of at least one weight-related comorbid condition (ie, hypertension, dyslipidemia, type 2 diabetes). ${ }^{17}$

With one-third of the adults living in the USA considered to be overweight and more than a third obese, a potentially huge market exists for lorcaserin. ${ }^{18}$ Thus, it is important to understand lorcaserin's side effect profile and its risk-to-benefit ratio. Despite the fact that the lorcaserin package insert states that it does not cause a significant increase in FDA-defined valvulopathy, defined as mitral regurgitation greater than mild or aortic regurgitation greater than trace (pooled relative risk (RR) of the phase 3 echocardiographic data: $1.16 ; 95 \%$ CI 0.81 to 1.67$),{ }^{17}$ a look at the FDA Medical Review states that lorcaserin causes a significant increase in moderate or greater mitral regurgitation at week 52 (RR 1.95; 95\% CI 1.05 to 3.59 , p value not stated) and (RR 1.88; 95\% CI 1.02 to $3.47, \mathrm{p}=0.04$ ) based on our forest plot) (figure 1). ${ }^{19}$ These data were based on a meta-analysis of three randomised controlled trials testing lorcaserin $10 \mathrm{mg}$ twice daily versus placebo. Moreover, the upper bound of the $95 \%$ CI (1.67) exceeded the 1.5 upper 
Figure 1 Relative risk of moderate or greater mitral regurgitation at week 52.

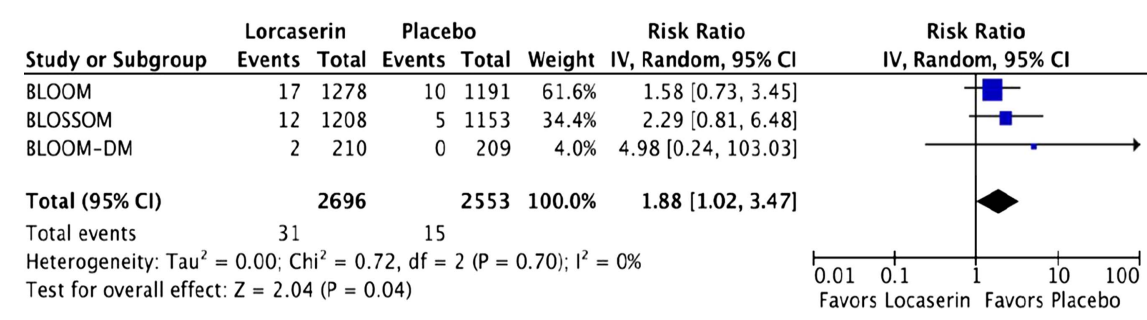

bound requested by the FDA to rule out an excess risk of valvular heart disease with lorcaserin. More data are certainly required to ascertain lorcaserin's risk of valvulopathy, ${ }^{20}$ as mitral regurgitation was consistently increased in the lorcaserin arm. ${ }^{19}$ In regard to the question if weight loss impacted mitral regurgitation, the lorcaserin FDA Medical Review specifically states, "mean weight loss in patients without FDA-defined valvular heart disease was $4.7 \mathrm{~kg}$, mean weight loss in patients with FDA-defined valvular heart disease at week 52 was $6.3 \mathrm{~kg}$. However, when three FDA-defined valvular heart disease outliers are removed, the mean change-and difference between groups-is attenuated (mean weight loss in patients with FDA-defined valvular heart disease (VHD) is $5.2 \mathrm{~kg}$ ) suggest that weight loss per se does not fully explain the difference in VHD between groups" (pages 73 and 74 of the FDA medical review).${ }^{19}$ As for any 5HT receptor agonist, lorcaserin may similarly act to cause valvular fibrosis and subsequent mitral regurgitation. It acts via the $5 \mathrm{HT}_{2 \mathrm{~B}}$ receptor widely expressed on valvular leaflets and pulmonary arteries. On activation of the $5 \mathrm{HT}_{2 \mathrm{~B}}$ receptor, phospholipase $\mathrm{C}-\beta$ is activated, which further activates protein kinase $\mathrm{C}$ (PKC). It also phosphorylates $\mathrm{Src}$ and thus activates extracellularregulated kinase 1(ERK1) and ERK2. ERK1 and ERK2 can also be activated by PKC itself. Along with this, 5HT itself and Src activate tissue growth factor $\beta$ receptor 1 (TGFBR1) leading to phosphorylation of SMAD-2 and SMAD-3 and formation of a complex with SMAD-4. This complex ultimately translocates to the nucleus to activate specific genes leading to the proliferation of valvular interstitial cells, secretion of increased glycosaminoglycans (probably through the upregulation of $5 \mathrm{HT}_{2 \mathrm{~B}} \mathrm{R}$ and downregulation of the 5HTT gene). This series of events ultimately results in a thickening of the valve with glycosaminoglycans (GAG)-rich fibromyxoid tissues, disorganisation of collagen fibres and neovascularisation leading to valvular regurgitation. ${ }^{21}$ The incidence of mitral regurgitation associated with lorcaserin does not seem to be explained by the reduced left ventricular ejection fraction. Rather, the reduced left ventricular ejection fraction may occur due to mitral regurgitation (secondary to the chronic left ventricular volume overload).

Of equal concern is the finding that lorcaserin seems to be associated with an increased incidence of depression (OR 1.89; 95\% CI1.04 to 3.44, $\mathrm{p}=0.04$ ) (figure 2) based on a pooled analysis of the same three randomised controlled trials testing lorcaserin $10 \mathrm{mg}$ twice daily versus placebo. In BLOOM-diabetes mellitus (DM), there was also an increase in adverse events related to ischaemic heart disease with lorcaserin versus placebo $(0.6 \%$ vs $0.4 \%$, respectively) with a twofold increased rate of cardiovascular death, non-fatal myocardial infarction or non-fatal stroke. ${ }^{19}$ Lastly, there may be an increase in 'possible' primary pulmonary hypertension with lorcaserin. Indeed, data derived from a pooled analysis of both BLOOM and BLOSSOM ( $\mathrm{n}=3470)$, using a $35 \mathrm{~mm} \mathrm{Hg}$ or greater increase in systolic arterial pulmonary pressure as a cut-off for 'possible' primary pulmonary hypertension, yield an increased risk with lorcaserin versus placebo (OR 1.41; $95 \%$ CI 0.87 to 2.27 , $\mathrm{p}=0.16) .{ }^{19}$ Although not a statistically significant finding, primary pulmonary hypertension is a very serious clinical adverse effect with a high mortality rate, and thus any possibility of an increased risk should be taken seriously.

The side effects of lorcaserin, related to valvulopathy (mitral regurgitation), possible increased systolic arterial pulmonary hypertension and depression, and possible increases in the risk of cardiovascular events would not be gleaned from a close reading of the package insert. As millions of people are overweight or obese, it is important to understand the side effects of lorcaserin before the widespread use of this medication occurs. Moreover, the effect size of lorcaserin's 3.3\% weight reduction (the mean placebo-subtracted weight loss at week 52 with lorcaserin $10 \mathrm{mg}$ twice daily from baseline from the pooled efficacy analysis ${ }^{19}$ appears trivial in the context of these potential side effects. Large randomised controlled trials are urgently required to fully elucidate the risk to benefit the profile of lorcaserin. Moving forward, a further assessment of mitral regurgitation or reanalysis of the available echocardiograms by an independent core laboratory

Figure 2 OR of depression.

\begin{tabular}{|c|c|c|c|c|c|c|c|}
\hline Study or Subgroup & \multicolumn{2}{|c|}{ Lorcaserin } & \multicolumn{2}{|c|}{ Placebo } & Weight & $\begin{array}{c}\text { Odds Ratio } \\
\text { IV, Random, } 95 \% \mathrm{CI}\end{array}$ & $\begin{array}{c}\text { Odds Ratio } \\
\text { IV, Random, } 95 \% \mathrm{Cl}\end{array}$ \\
\hline BLOSSOM + BLOOM & 29 & 3195 & 16 & 3185 & $96.1 \%$ & $\quad 1.81[0.98,3.35]$ & \\
\hline BLOOM-DM & 2 & 256 & 0 & 252 & $3.9 \%$ & $4.96[0.24,103.84]$ & \\
\hline Total $(95 \% \mathrm{Cl})$ & & 3451 & & 3437 & $100.0 \%$ & $1.89[1.04,3.44]$ & \\
\hline Total events & 31 & & 16 & & & & \\
\hline $\begin{array}{l}\text { Heterogeneity: } \text { Tau }^{2} \\
\text { Test for overall effec }\end{array}$ & $\begin{array}{l}0.00 ; C \\
Z=2.0\end{array}$ & $\begin{array}{l}\mathrm{i}^{2}=0 . \\
7(\mathrm{P}=0\end{array}$ & $\begin{array}{l}40, \mathrm{df}= \\
.04)\end{array}$ & $1(P=$ & $0.53) ; 1^{2}=$ & & $\begin{array}{ccccc}0.01 & 0.1 & 1 & 10 & 100 \\
\text { Favors } & \text { Locaserin } & \text { Favors Placebo }\end{array}$ \\
\hline
\end{tabular}


could provide more insight on this issue. At the very least, moderate or greater mitral regurgitation should be added to lorcaserin's package insert, and the possibility of a significant increased risk of depression should also be added, so that clinicians and patients alike are aware of these potential side effects.

Contributors JJD, SC and PM wrote the manuscript. JHO reviewed and edited the manuscript.

Competing interests None.

Provenance and peer review Not commissioned; internally peer reviewed.

Open Access This is an Open Access article distributed in accordance with the Creative Commons Attribution Non Commercial (CC BY-NC 4.0) license, which permits others to distribute, remix, adapt, build upon this work noncommercially, and license their derivative works on different terms, provided the original work is properly cited and the use is non-commercial. See: http:// creativecommons.org/licenses/by-nc/4.0/

\section{REFERENCES}

1. Marcason W. What are the latest figures for state-specific prevalence of obesity in the United States? J Am Diet Assoc 2007:107:168.

2. Zaninotto P, Head J, Stamatakis E, et al. Trends in obesity among adults in England from 1993 to 2004 by age and social class and projections of prevalence to 2012. J Epidemiol Community Health 2009;63:140-6.

3. Jafar TH, Qadri Z, Islam M, et al. Rise in childhood obesity with persistently high rates of undernutrition among urban school-aged Indo-Asian children. Arch Dis Child 2008;93:373-8.

4. World Health Organization Obesity and overweight fact sheet no. 311. 2006. WHO website. http://www.who.int/mediacentre/ factsheets/fs311/en/ (accessed 7 Sep 2013).

5. Flegal KM, Carroll MD, Ogden CL, et al. Prevalence and trends in obesity among US adults, 1999-2008. JAMA 2010;303:235-41.

6. Danaei G, Ding EL, Mozaffarian D, et al. The preventable causes of death in the United States: comparative risk assessment of dietary, lifestyle, and metabolic risk factors. PLoS Med 2009;6:e1000058.
7. Wing RR; Look AHEAD Research Group. Long-term effects of a lifestyle intervention on weight and cardiovascular risk factors in individuals with type 2 diabetes mellitus: four-year results of the Look AHEAD trial. Arch Intern Med 2010;170:1566-75.

8. Mertens IL, van Gaal LF. Overweight, obesity, and blood pressure: the effects of modest weight reduction. Obes Res 2000;8:270-8.

9. Fontana MA, Wohlgemuth SD. The surgical treatment of metabolic disease and morbid obesity. Gastroenterol Clin North Am 2010;39:125-33.

10. Jensen C, Flum DR. The costs of nonsurgical and surgical weight loss interventions: is an ounce of prevention really worth a pound of cure? Surg Obes Relat Dis 2005;1:353-7.

11. Tindle HA, Omalu B, Courcoulas A, et al. Risk of suicide after long-term follow-up from bariatric surgery. Am J Med 2010;123:1036-42.

12. Colman E, Golden J, Roberts M, et al. The FDA's assessment of two drugs for chronic weight management. N Engl J Med 2012;367:1577-9.

13. Hopkins CR. ACS chemical neuroscience molecule spotlight on Iorcaserin. ACS Chem Neurosci 2010;1:718-19.

14. Thomsen WJ, Grottick AJ, Menzaghi F, et al. Lorcaserin, a novel selective human 5-hydroxytryptamine2C agonist: in vitro and in vivo pharmacological characterization. J Pharmacol Exp Ther 2008;325:577-87.

15. Smith BM, Smith JM, Tsai JH, et al. Discovery and structure-activity relationship of (1R)-8-chloro-2,3,4,5-tetrahydro-1-methyl-1H-3benzazepine (Lorcaserin), a selective serotonin 5-HT2C receptor agonist for the treatment of obesity. J Med Chem 2008;51:305-13.

16. Bello NT and Liang N. The use of serotonergic drugs to treat obesity -is there any hope? Drug Des Devel Ther 2011;5:95-109.

17. Belviq (lorcaserin hydrochloride) package insert. Zofingen, Switzerland: Arena Pharmaceuticals GmbH; June 2012. http://www.belviq.com/pdf/ Belviq_Prescribing_information.pdf (accessed 8 Sep 2013).

18. Prevalence of overweight, obesity, and extreme obesity among adults. Centers for Disease Control, 2011. http://www.cdc.gov/nchs/ data/hestat/obesity_adult_09_10/obesity_adult_09_10.htm (accessed 8 Sep 2013)

19. The FDA Lorcaserin Medical Review. http://www.accessdata.fda. gov/drugsatfda_docs/nda/2012/0225290rig1s000MedR.pdf (accessed 8 Sep 2013)

20. Weissman NJ, Sanchez M, Koch GG, et al. Echocardiographic assessment of cardiac valvular regurgitation with lorcaserin from analysis of 3 phase 3 clinical trials. Circ Cardiovasc Imaging 2013;6:560-7.

21. Elangbam CS. Drug-induced valvulopathy: an update. Toxicol Pathol 2010;38:837-48. 